\title{
In-situ Investigations of the Hydrogen Uptake of Zirconium Alloys during Steam Oxidation
}

\section{Grosse, M. Steinbrueck, B. Schillinger, A. Kaestner}




\section{Outline}

- Introduction

- Neutron Imaging

- Results

- Examples

- In-situ Calibration

- Analyse of the data

- Discussion

- Conclusions 


\section{Introduction}

- Zirconium alloys absorb hydrogen during corrosion in water or steam oxidation at higher temperatures

- Hydrogen uptake reduces the ductility of zirconium alloys

- Consequences for the thermo-shock stability during LOCA

- QUENCH-LOCA program was initiated at KIT to study the hydrogen uptake during LOCA and its consequences on the mechanical properties

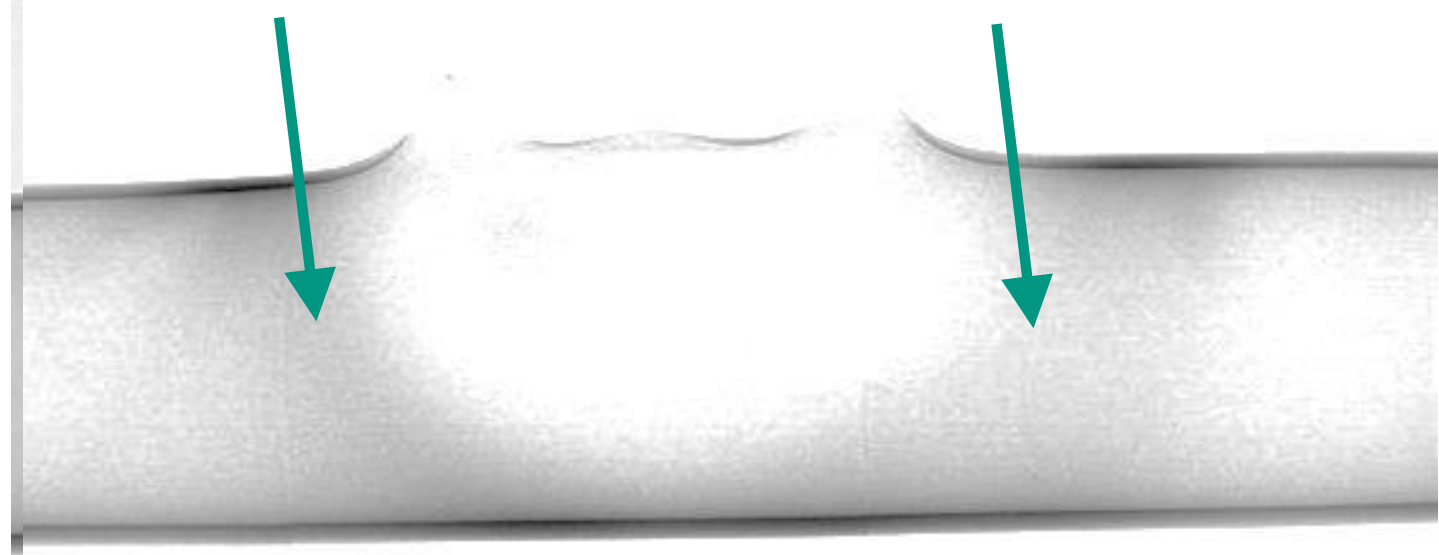

Neutron radiograph of the balloning zone of rod \#08 of the QUENCH-LO-test 


\section{Neutron Imaging}

$$
\begin{aligned}
\text { Beer-Lamberts law: } & I=I_{0} \exp (-\Sigma s) \\
\text { with } & \Sigma=\sum_{i}\left(N_{i} \sigma_{i}\right)
\end{aligned}
$$

X-ray

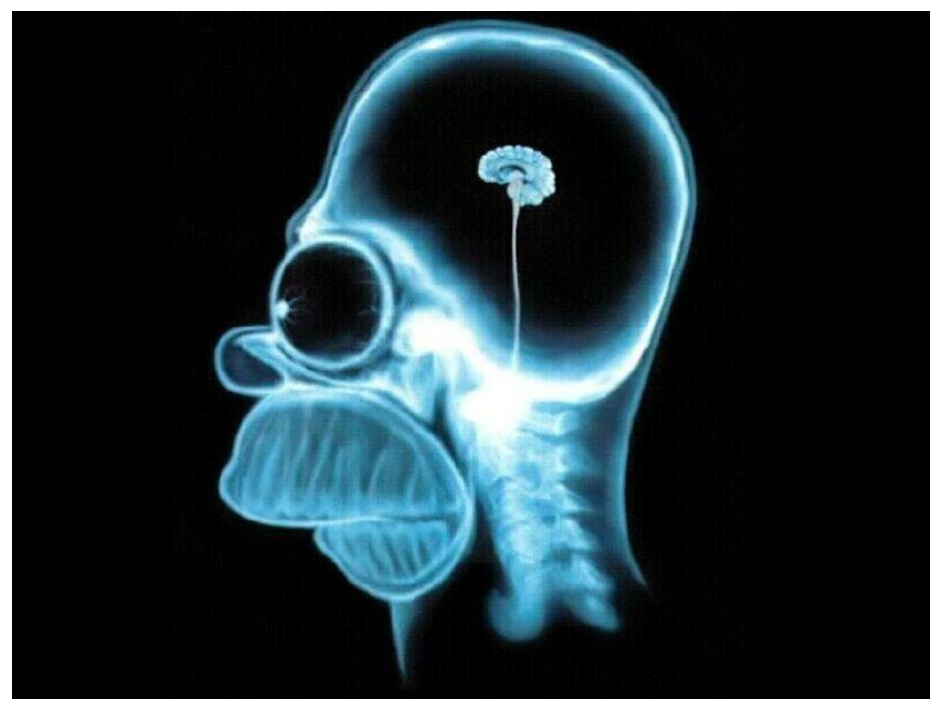

$$
\sigma=f(Z)
$$

Neutrons

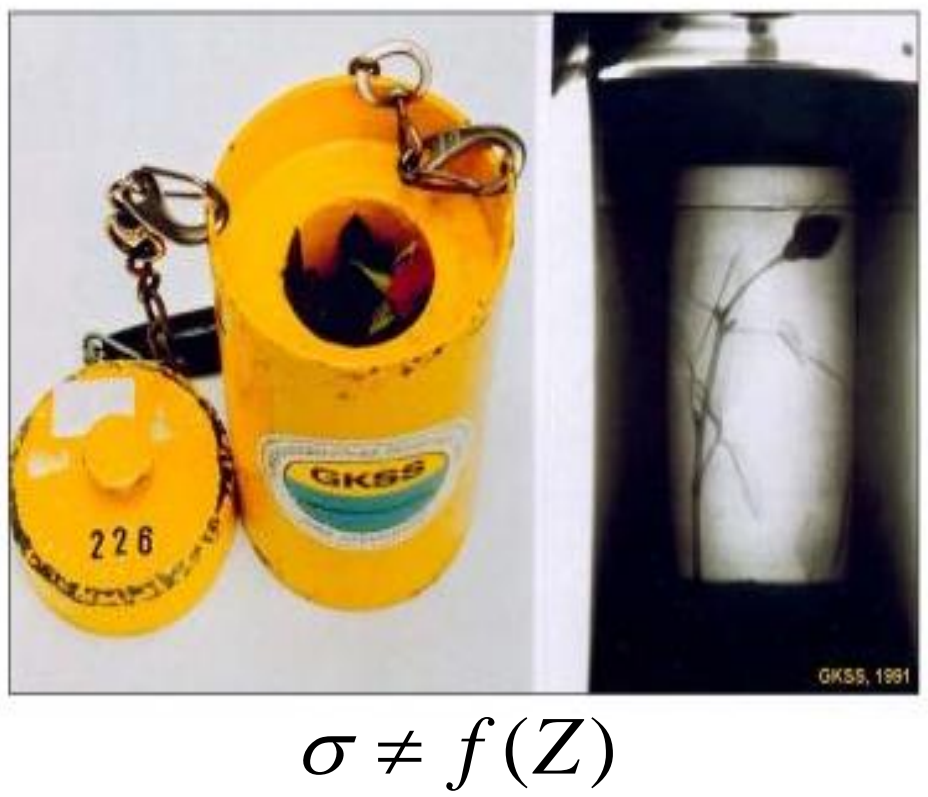

$$
\sigma_{H}>>\sigma_{Z r}
$$




\section{Neutron Imaging}

$$
\begin{aligned}
\Sigma_{\text {total }} & =\frac{-\ln \left(\frac{I-I_{B}}{I_{0}-I_{B}}\right)}{s} \\
& =\quad \sum_{i} N_{i} \sigma_{i} \\
& =\underbrace{N_{Z r} \sigma_{Z r}+\ldots .}_{\Sigma_{Z r y}}+N_{H} \sigma_{H}+N_{O} \sigma_{O}
\end{aligned}
$$

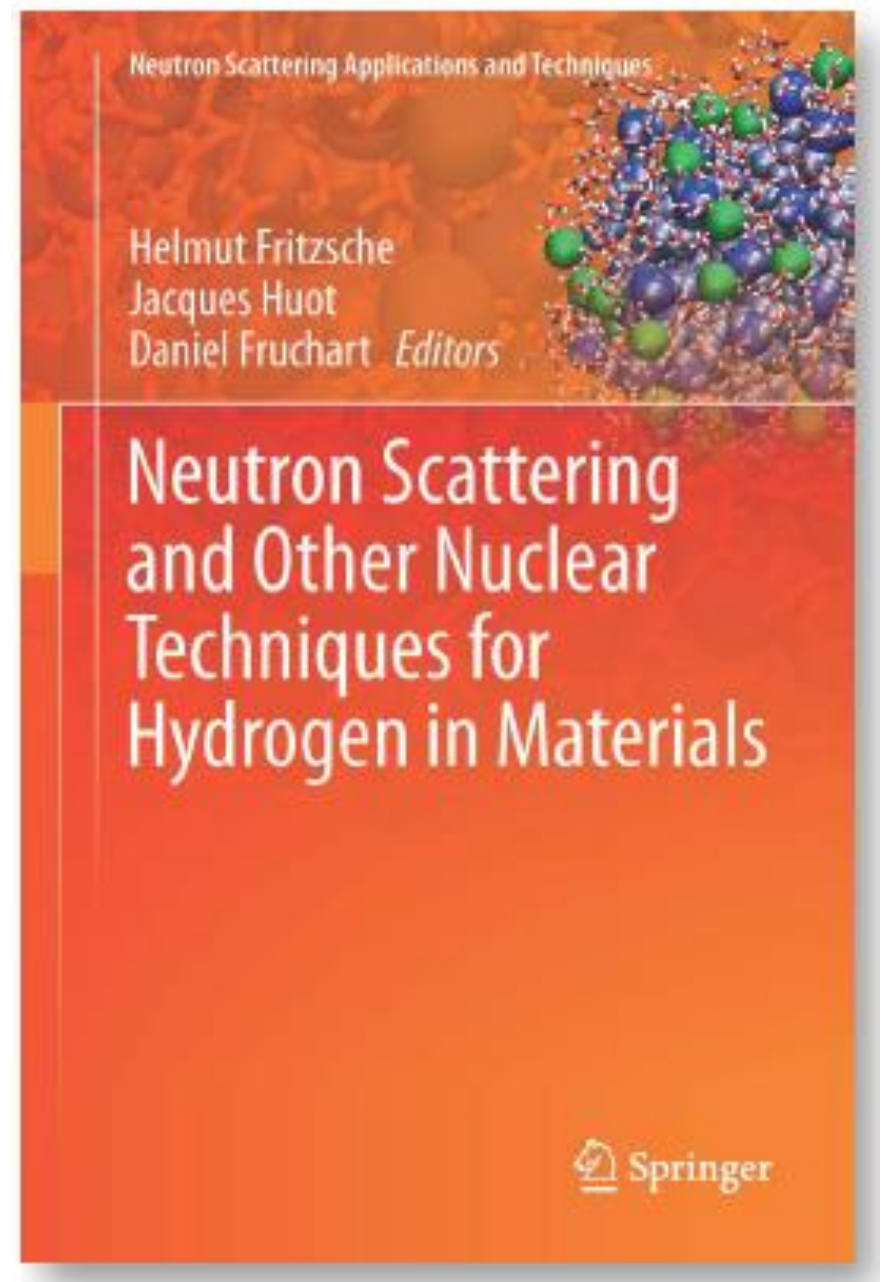




\section{Materials and Experiments}

- Materials: Zry-4 and traditional E110

- Temperatures:

$$
\begin{aligned}
& \text { Zry-4: } 1273,1373,1473 \text { and } 1573 \mathrm{~K} \\
& \text { E110: }(1123,1173,) 1273,1373,121473 \text { and } 1573 \mathrm{~K}
\end{aligned}
$$

- Neutron radiography measurements:

- ICON at SINQ, 120 and 20 s illumination per image

- ANTARES at FRM-2, $10 \mathrm{~s}$ illumination per image
- INRRO furnace:

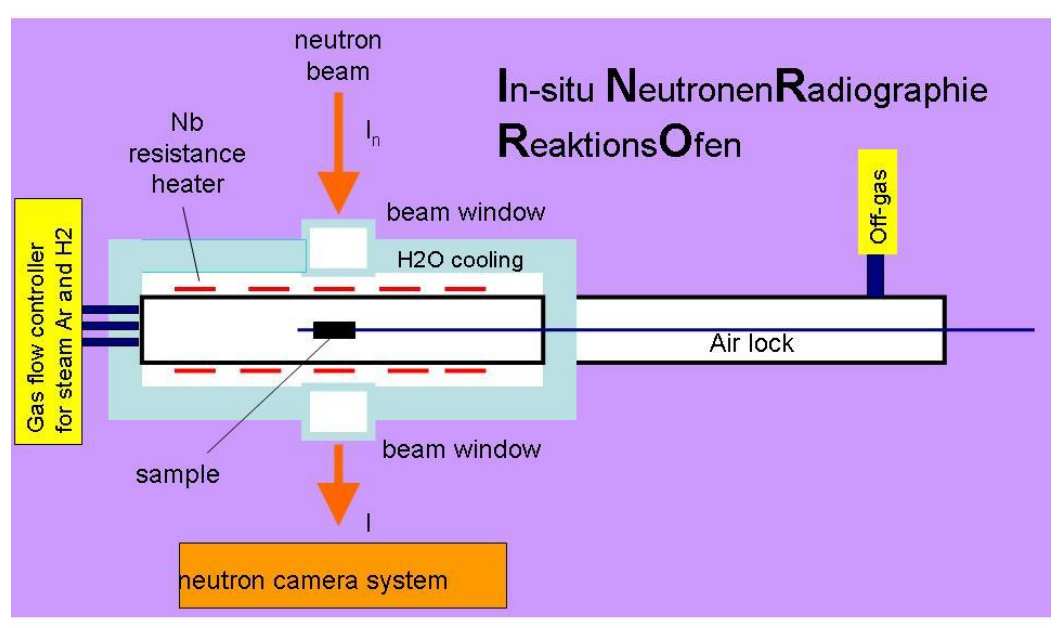

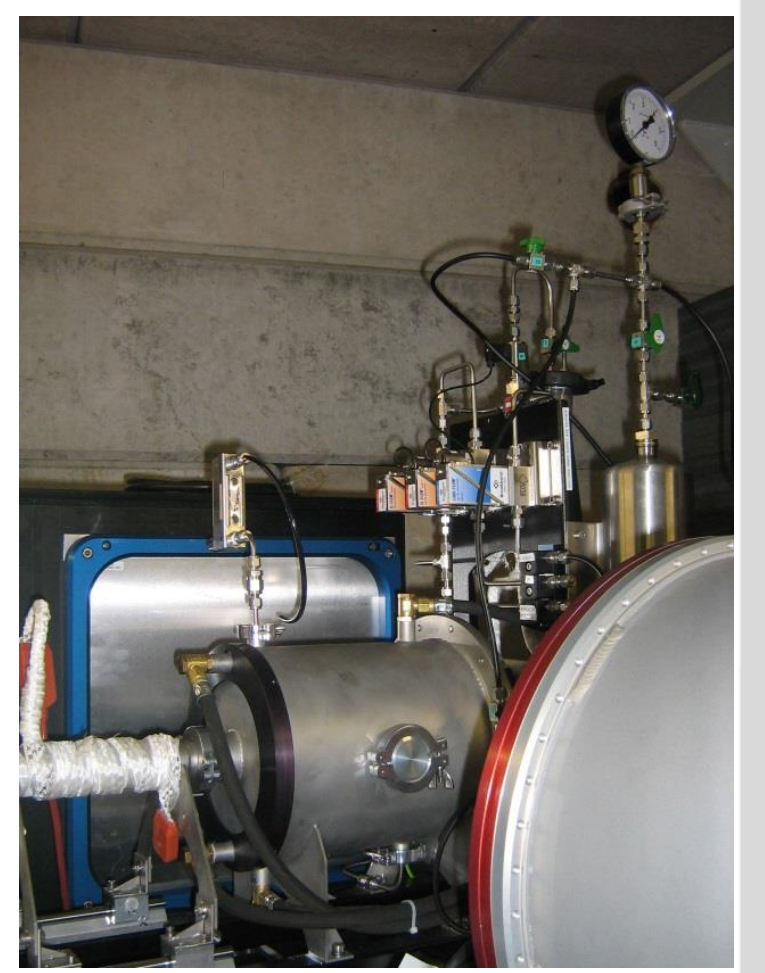

$6 / 22$ Mirco Grosse et al. / $18^{\text {th }}$ Inten. Symposium on Zirconium in Nuclear Industries / Hilton Head Island / May 15-18 2016
Institute for Applied Materials Program NUSAFE 


\section{Results Examples}

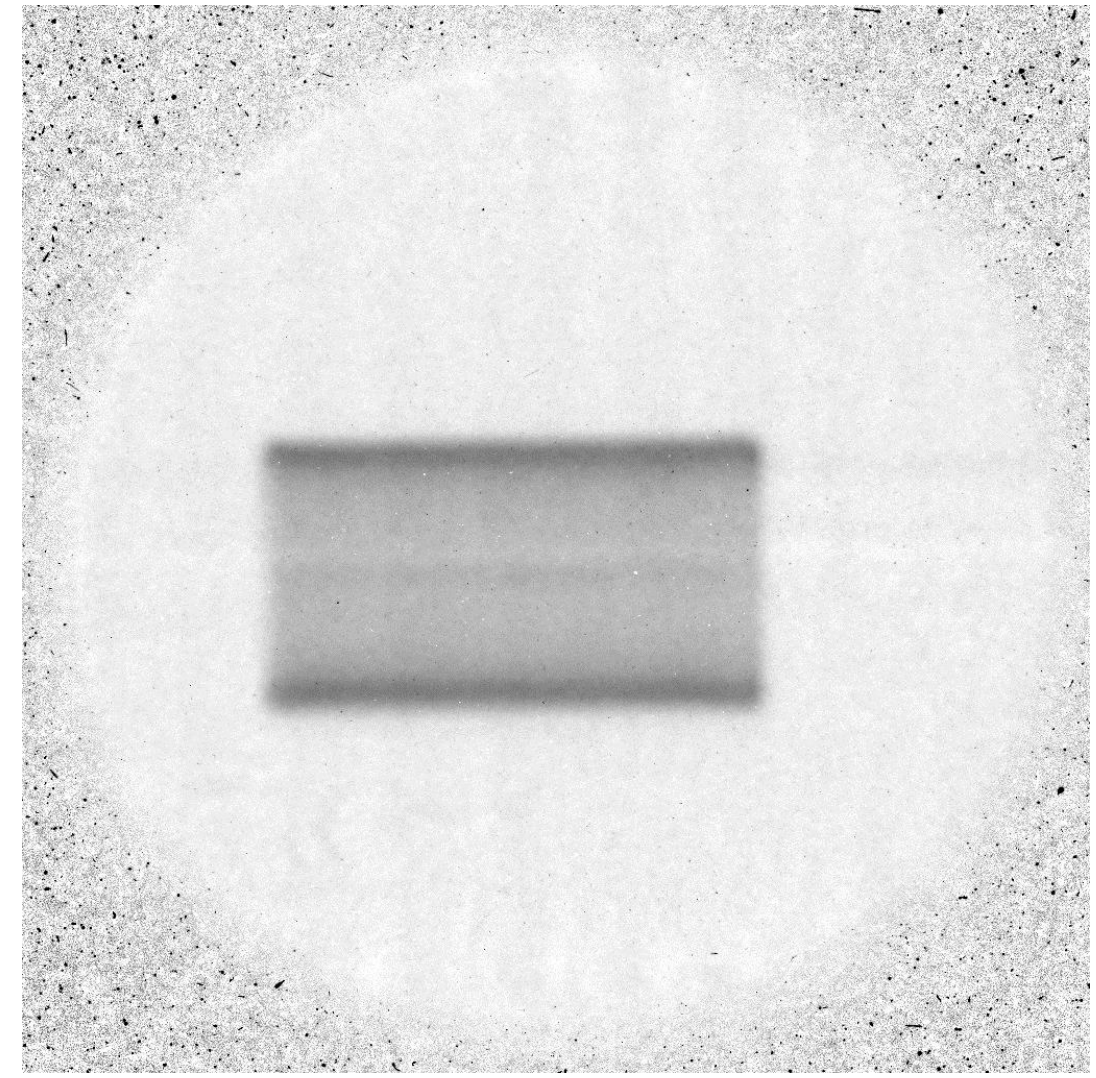

Zry-4, $1373 \mathrm{~K}$

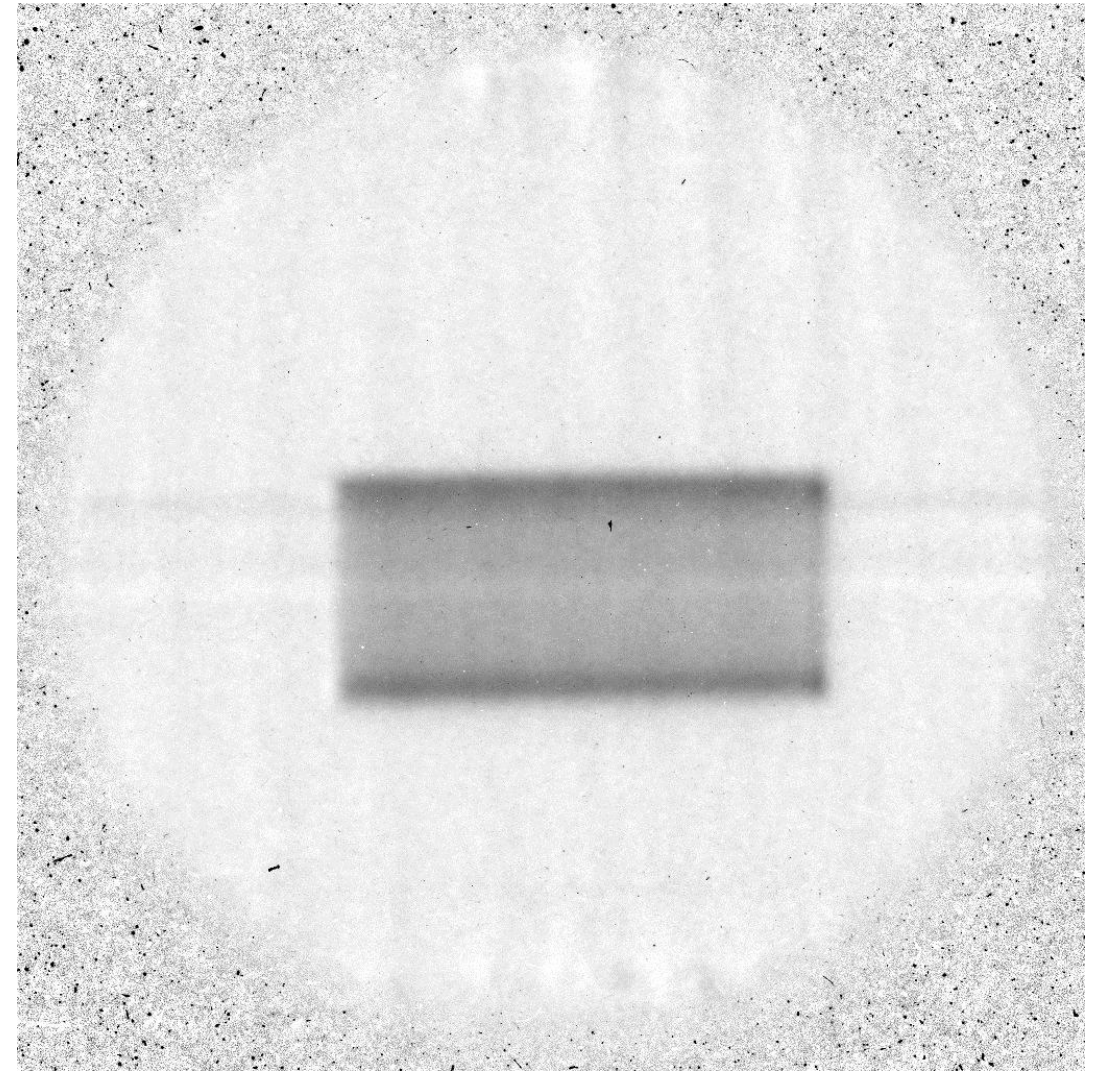

E110, $1473 \mathrm{~K}$ 


\section{Results Examples}

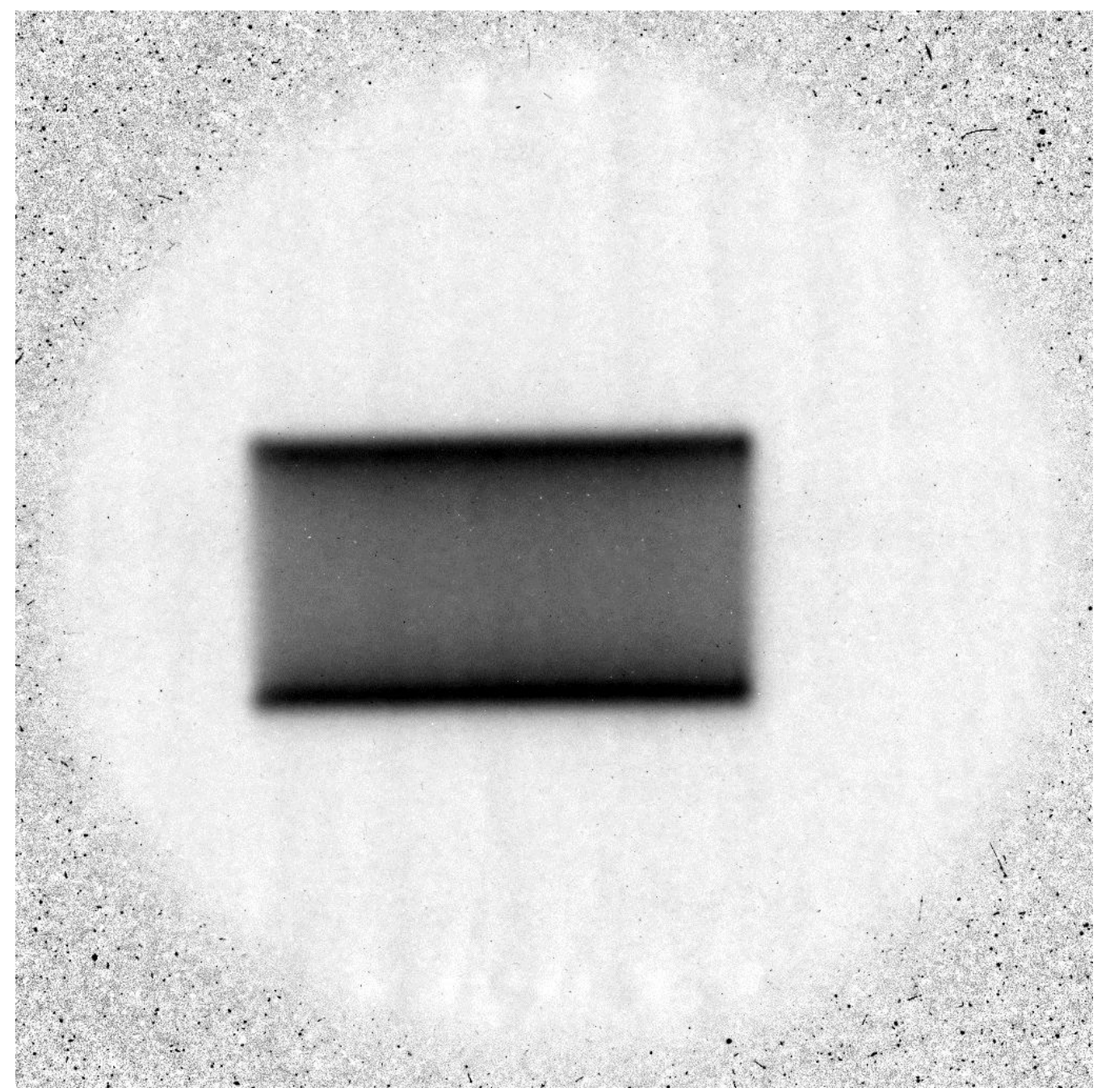

Zry-4, $1273 \mathrm{~K}$ 


\section{Calibration - Effect of Hydrogen}

Sieverts' law:

$$
\begin{aligned}
C_{H}^{(m)} & =K_{S} \cdot \sqrt{p_{H_{2}}} \\
K_{S} & =\exp \left(\frac{\Delta_{S} S}{R}-\frac{\Delta_{S} H}{R \cdot T}\right)
\end{aligned}
$$

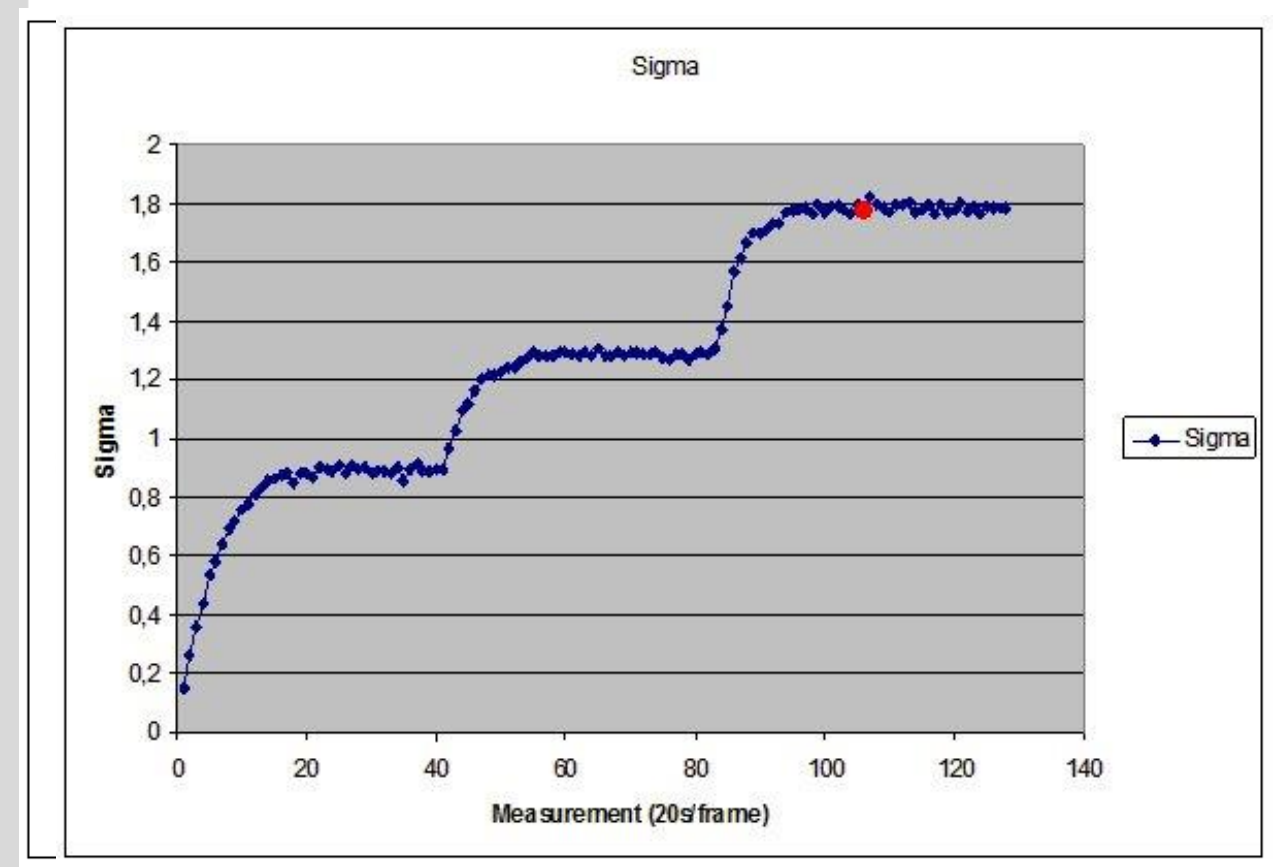

\section{$2 \mathrm{l} / \mathrm{h}$}

\section{$4 \mathrm{l} / \mathrm{h}$}

$8 \mathrm{l} / \mathrm{h} \quad \mathrm{H}_{2}, 50 \mathrm{l} / \mathrm{h} \mathrm{Ar}$

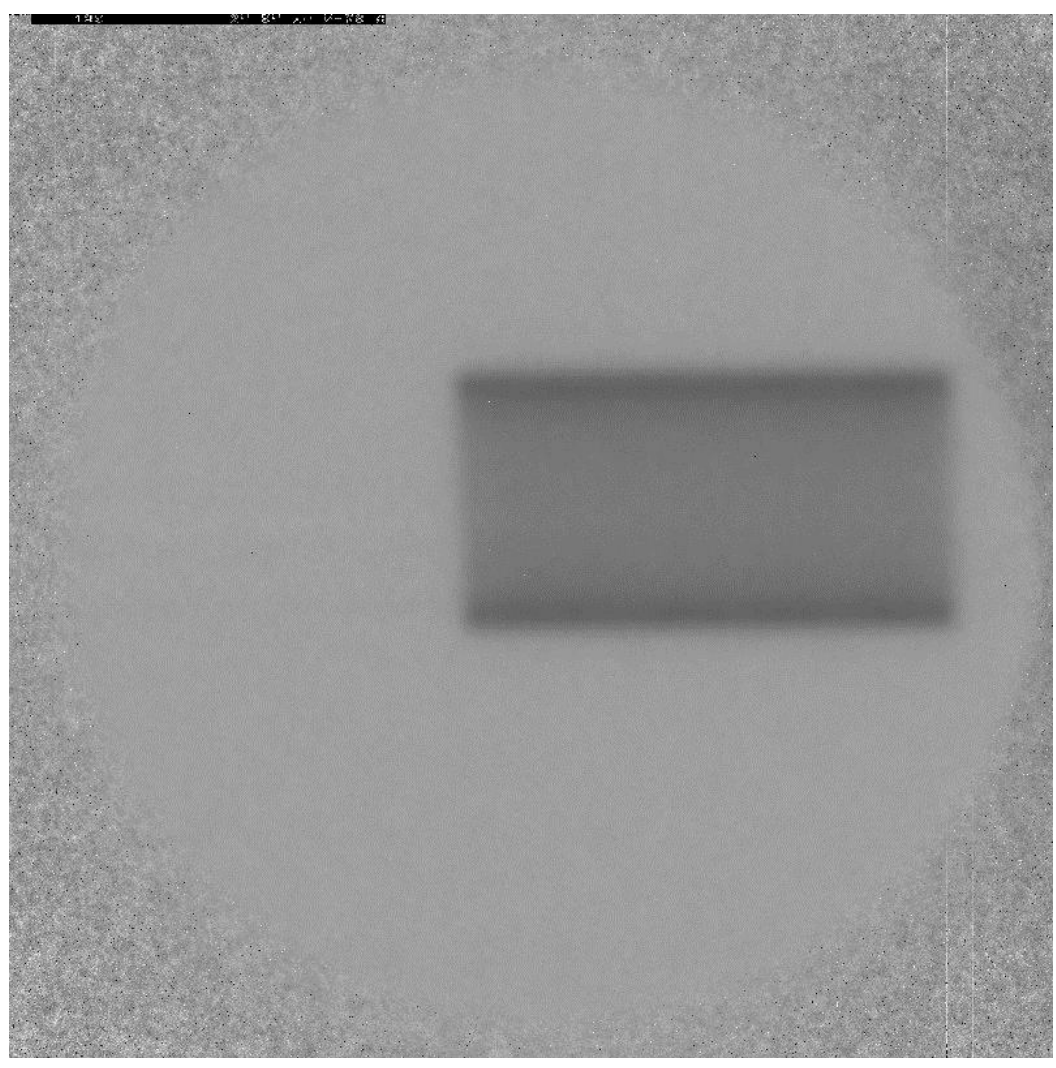




\section{Calibration - Effect of Hydrogen}

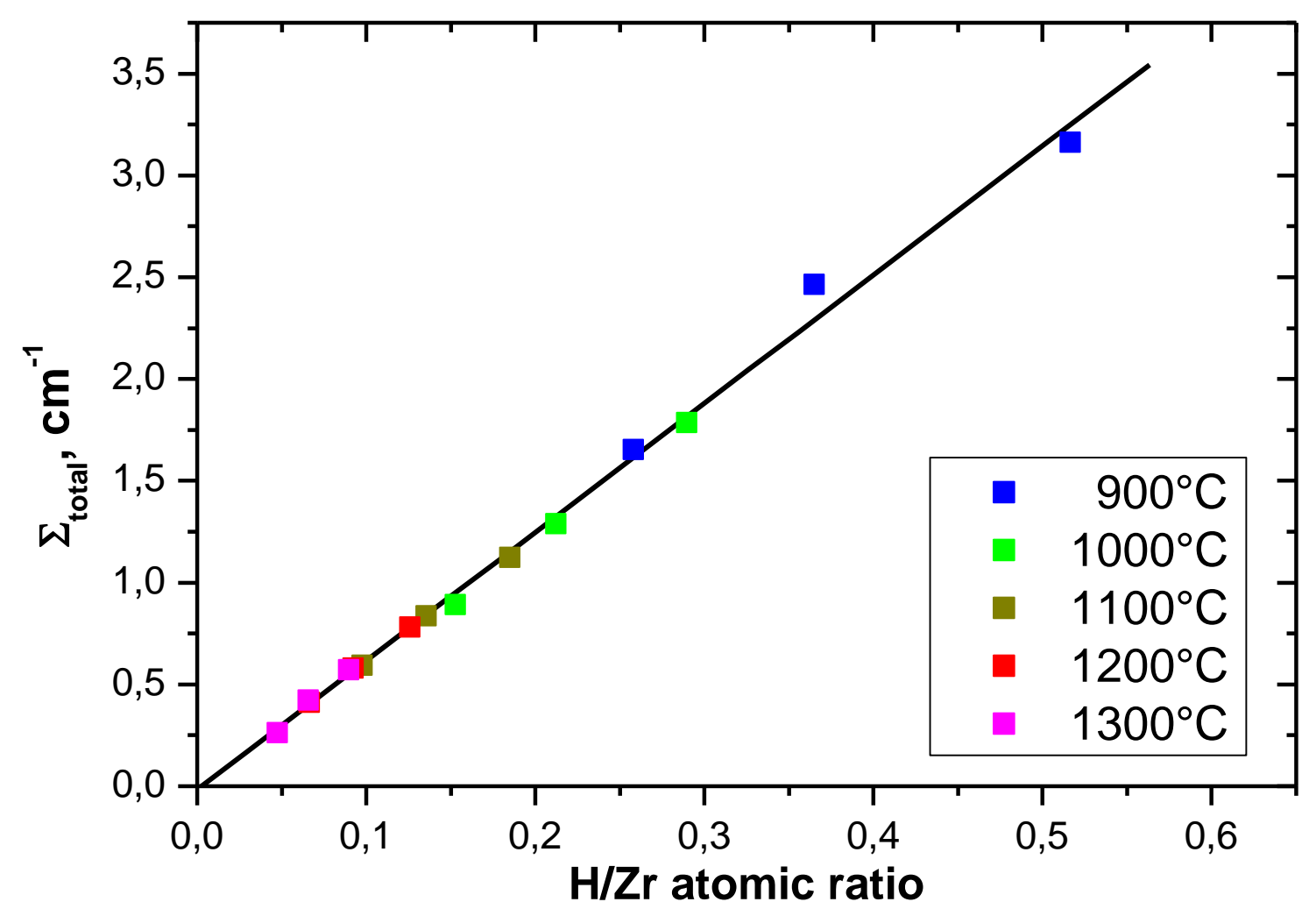

For in-situ NR experiments at SINQ:

$\Sigma_{\text {total }}=6.32 \pm 0.12 \mathrm{H} / \mathrm{Zr}$

For in-situ NR experiments at FRM2:

$\Sigma_{\text {total }}=5.61 \pm 0.28 \mathrm{H} / \mathrm{Zr}$ 
$\Sigma_{o}=N_{o} \sigma_{o}=(0.98 \pm 0.04) \mathrm{cm}^{-1} \frac{\Delta m}{m}$

\section{Calibration - Effect of Oxygen}

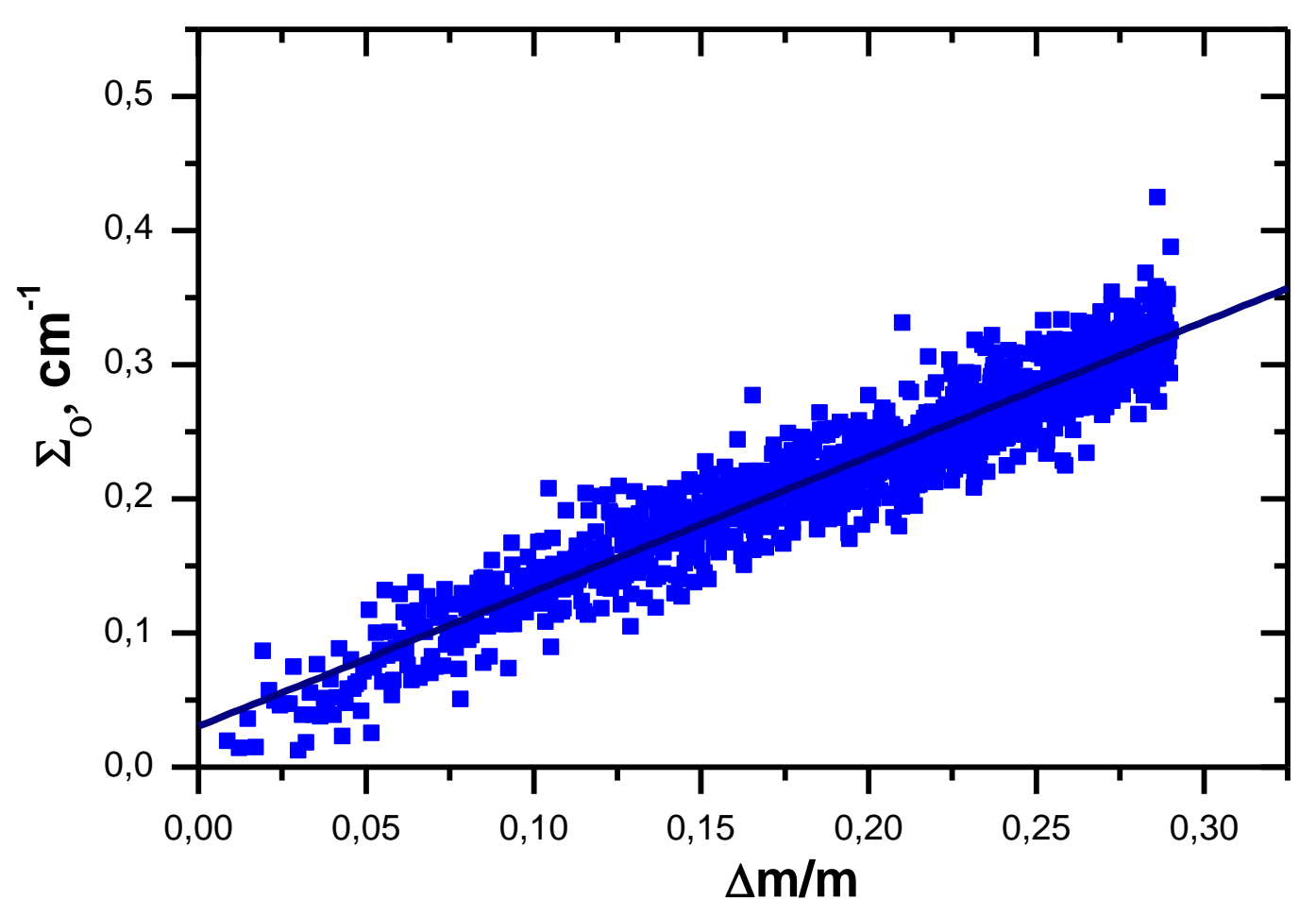

Annealing in $\mathrm{Ar} / \mathrm{O}_{2}$ at $1200^{\circ} \mathrm{C}$

$$
\Sigma_{O}=N_{o} \sigma_{O}=(0.98 \pm 0.04) \mathrm{cm}^{-1} \frac{\Delta m}{m}
$$




\section{Results data correction}

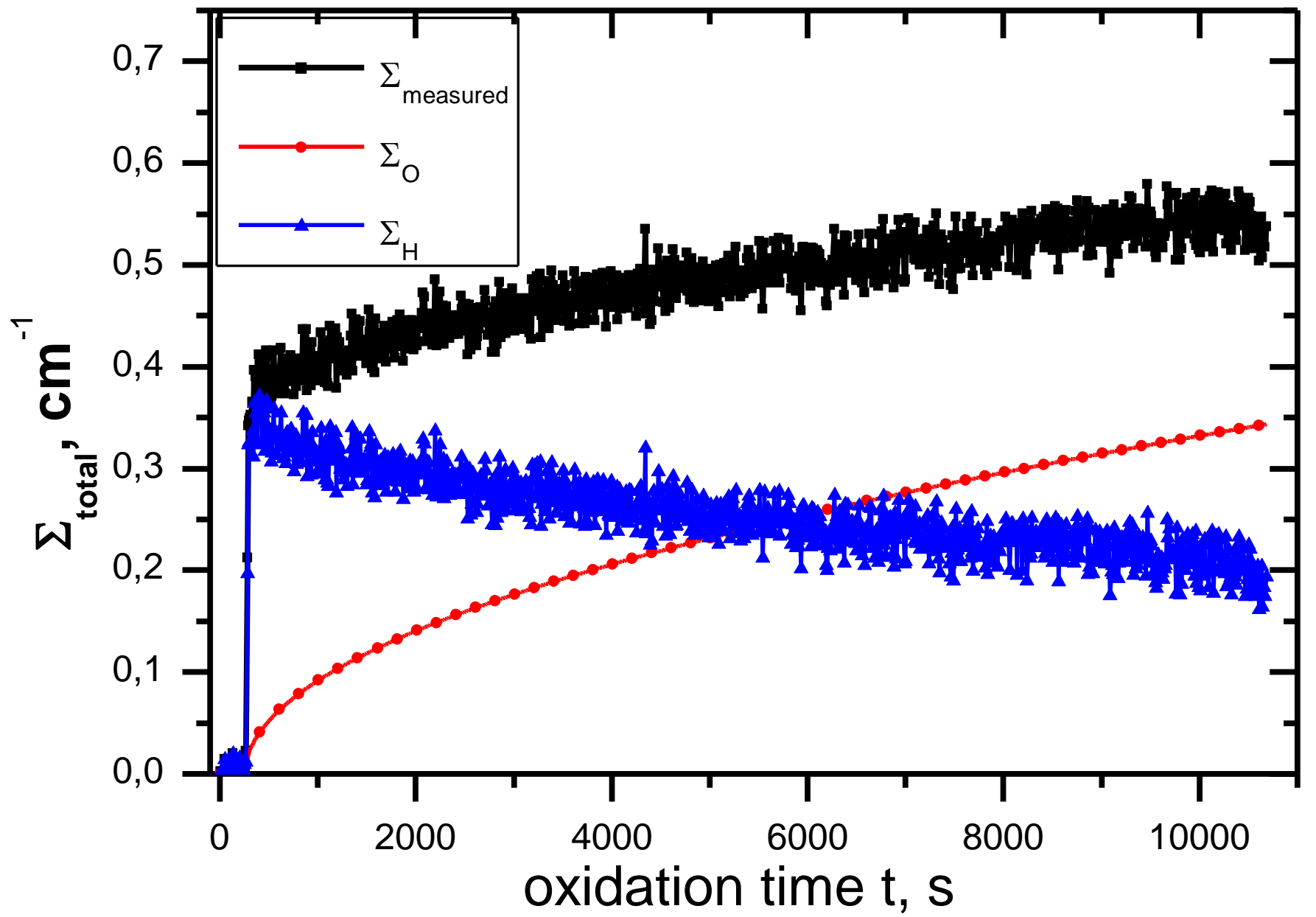

\section{Zry-4, $1473 \mathrm{~K}$}




\section{Results}

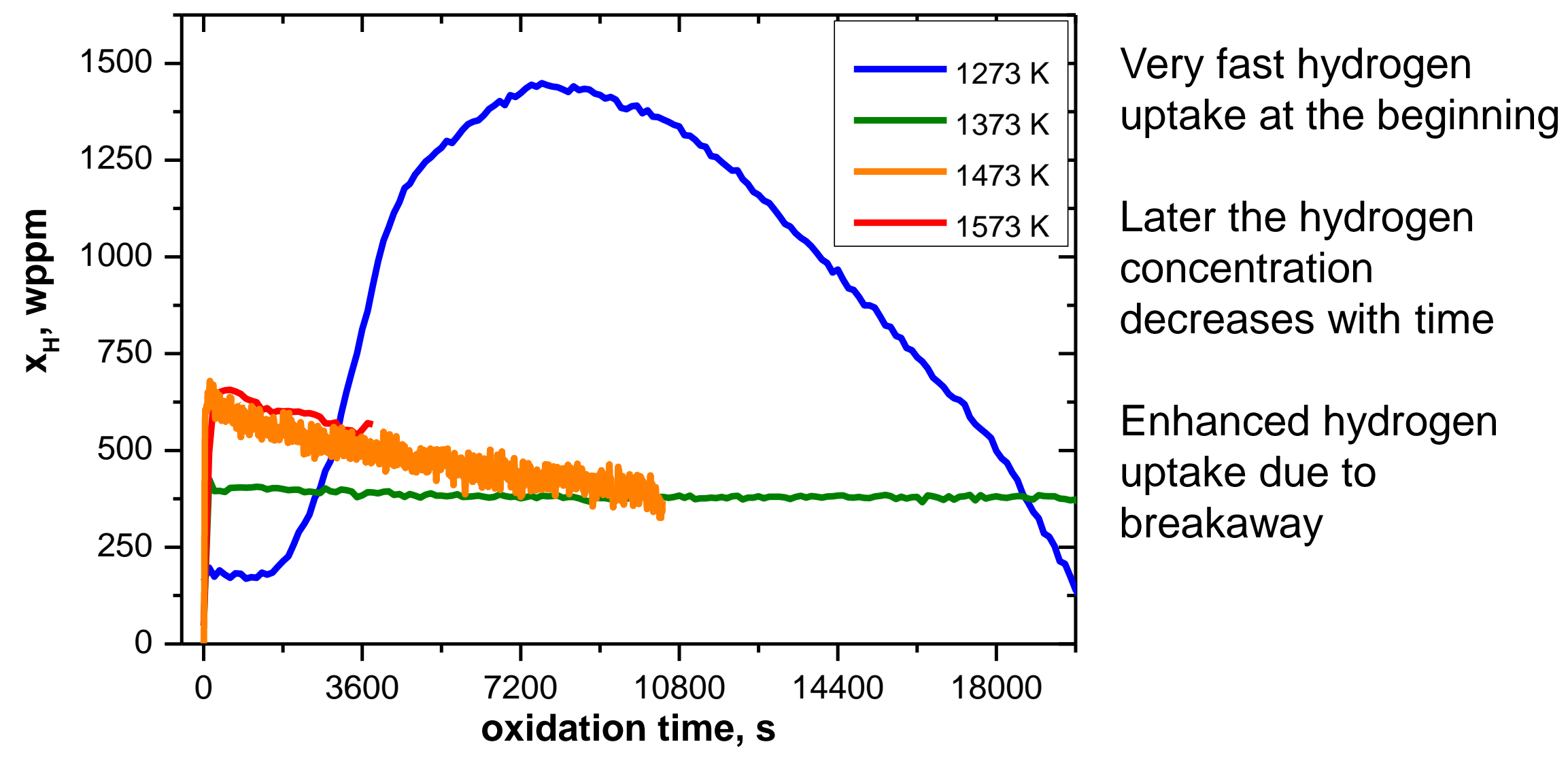




\section{Results}

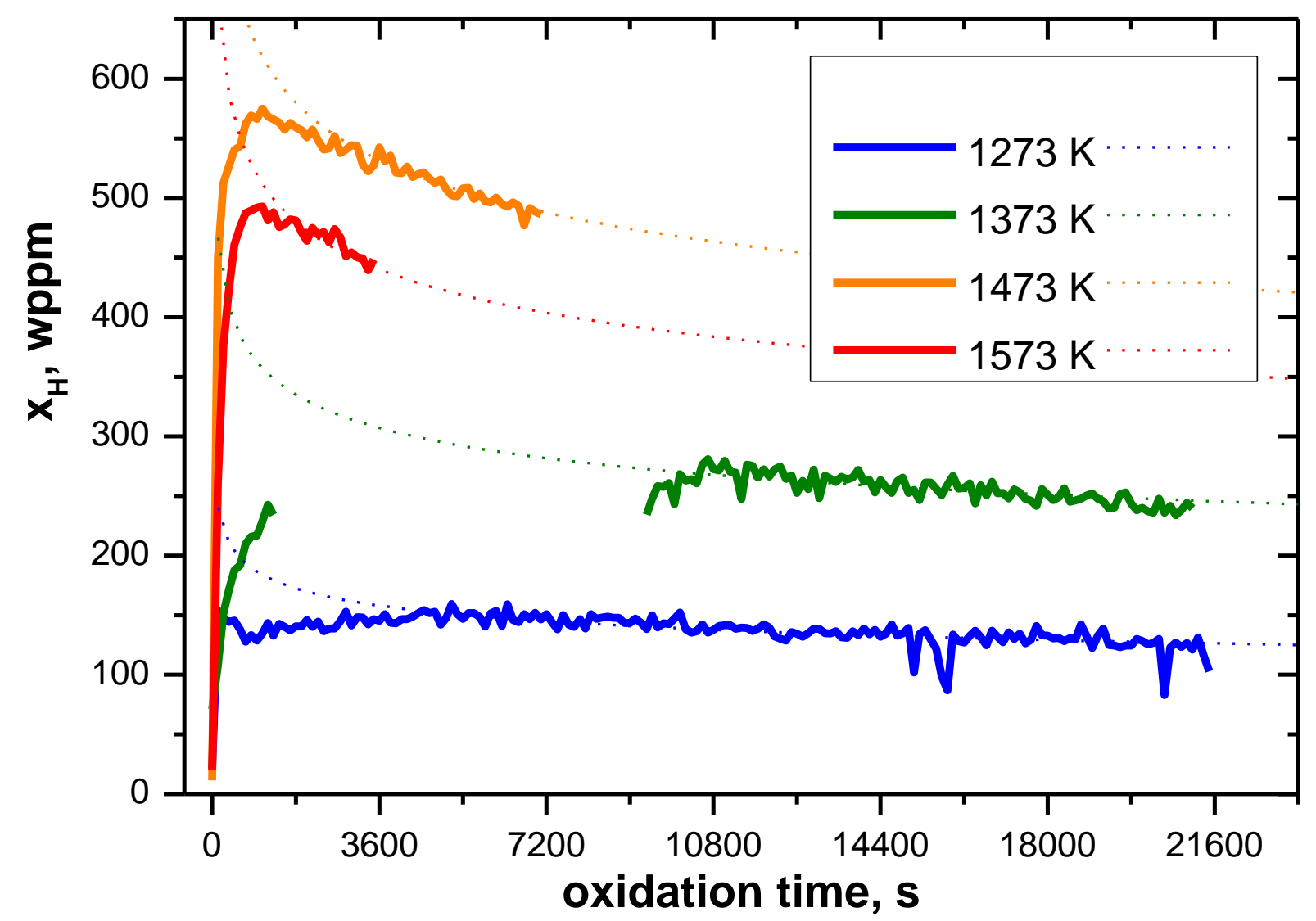

Very fast hydrogen uptake at the beginning

Later the hydrogen concentration decreases with time

Less influence of breakaway on the hydrogen concentration 


\section{Discussion}

Hydrogen pump effect during breakaway oxidation

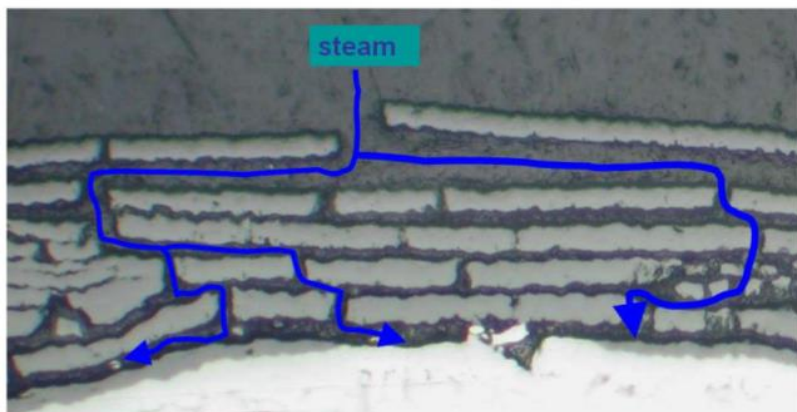

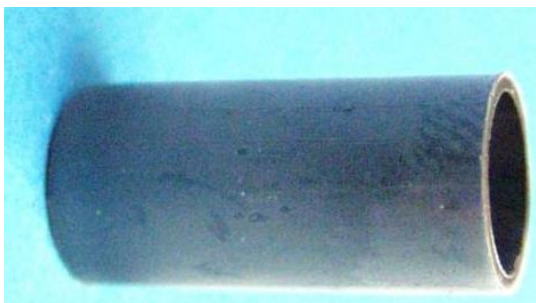

E110

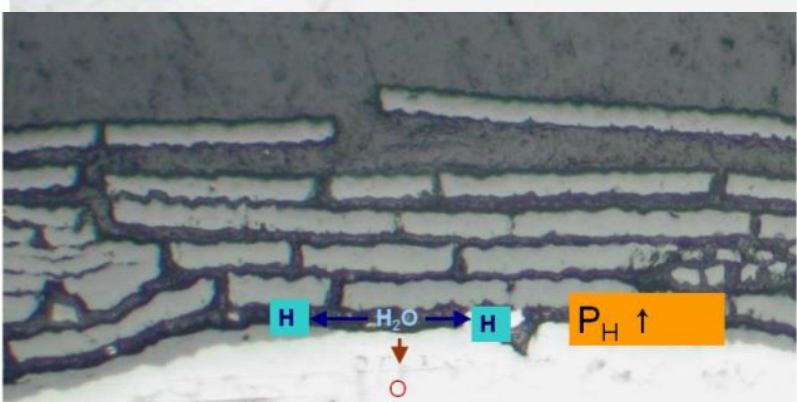

$1273 \mathrm{~K}, 4 \mathrm{~h}$ in steam
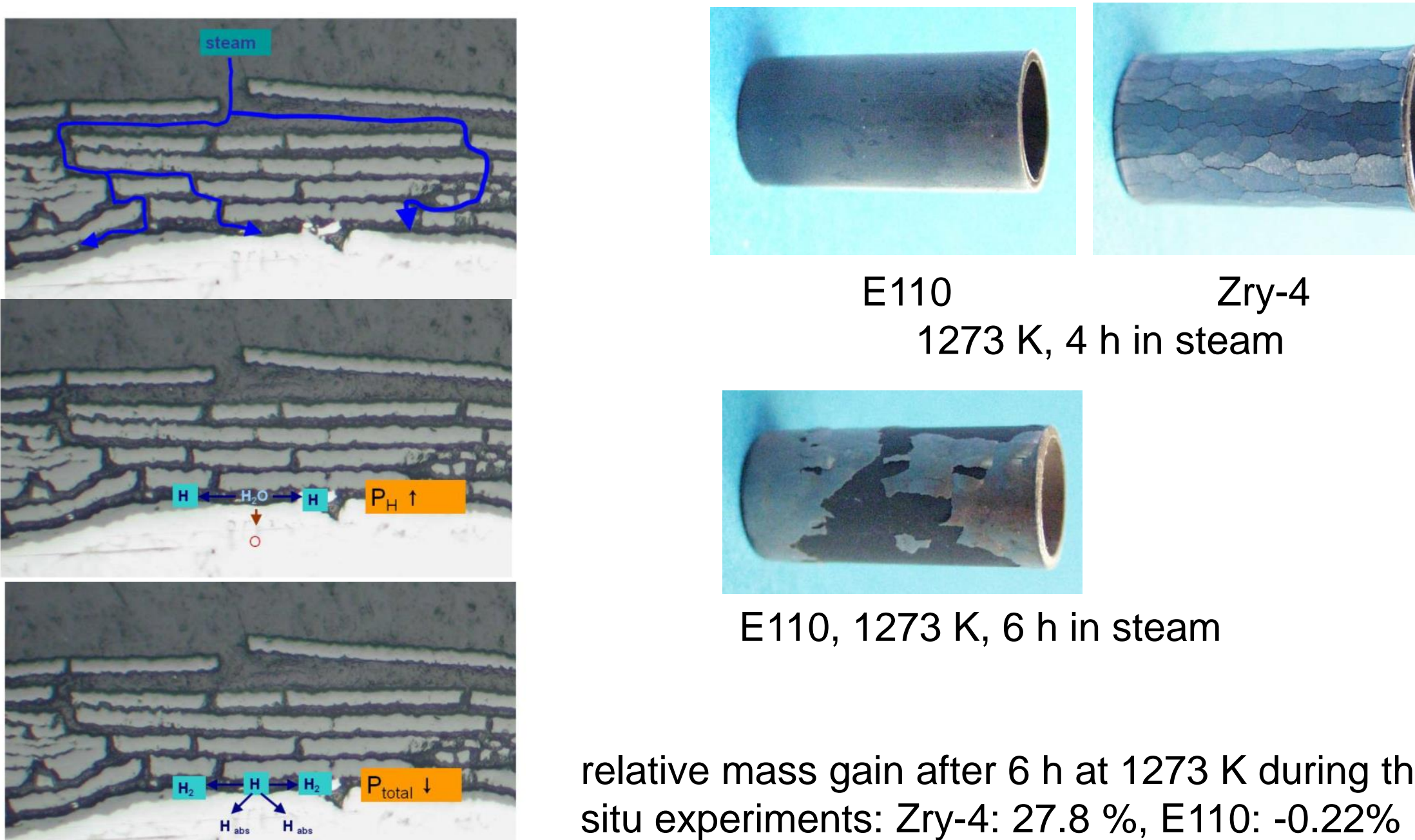

Zry-4

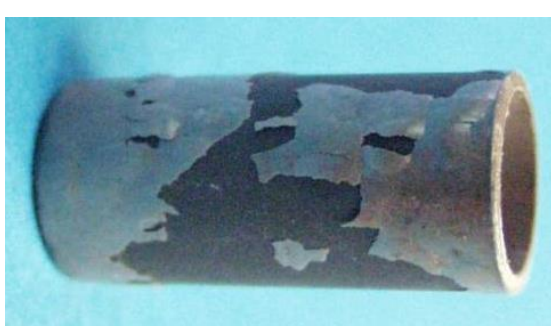

$\mathrm{E} 110,1273 \mathrm{~K}, 6 \mathrm{~h}$ in steam

relative mass gain after $6 \mathrm{~h}$ at $1273 \mathrm{~K}$ during the insitu experiments: Zry-4: $27.8 \%$, E110: $-0.22 \%$ 


\section{Discussion}

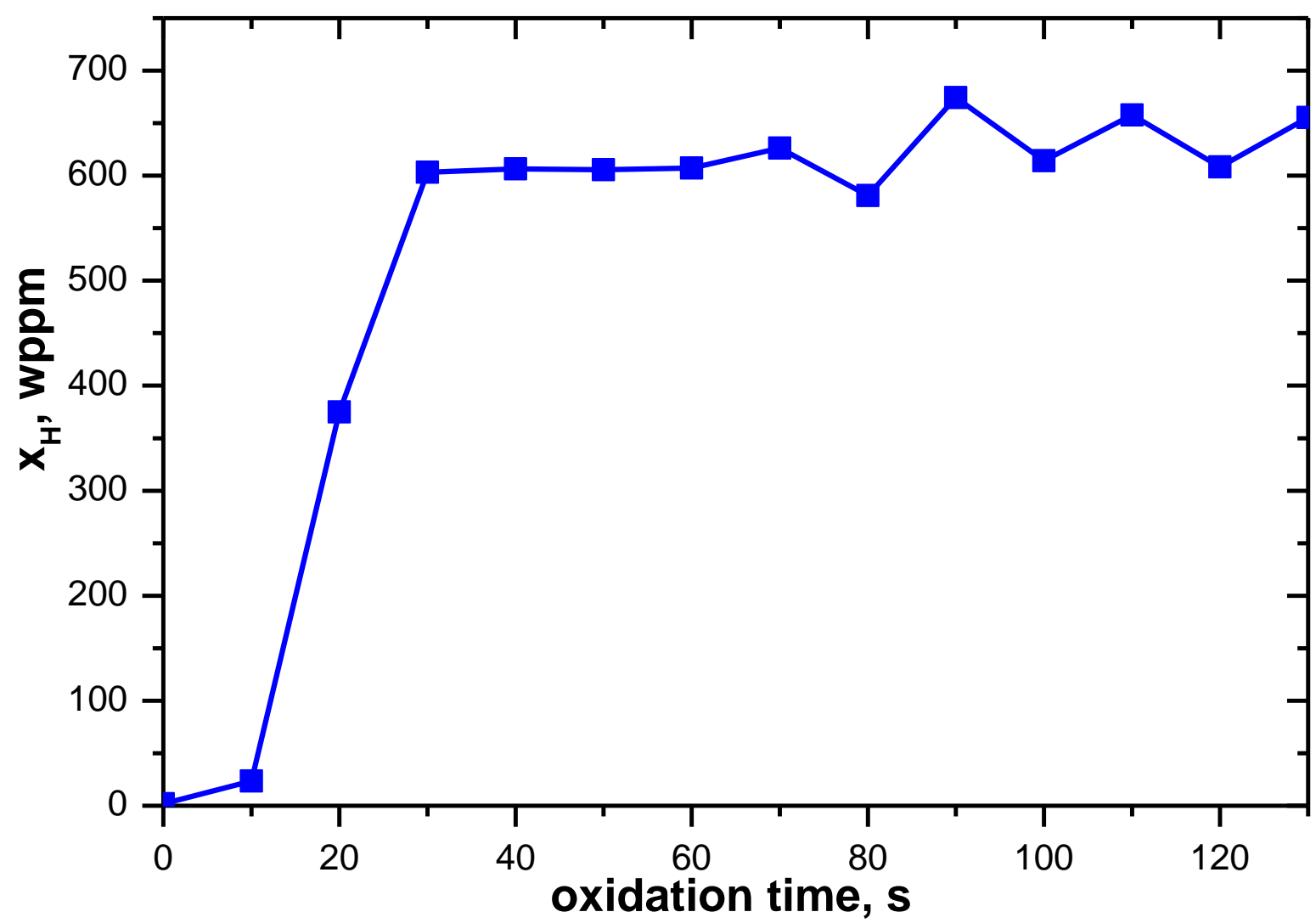

- very fast hydrogen uptake at the beginning

- during the first $20 \mathrm{~s}$ the whole hydrogen uptake occurs

- explains the results obtained from the QUENCH-LOCA tests 


\section{Discussion}

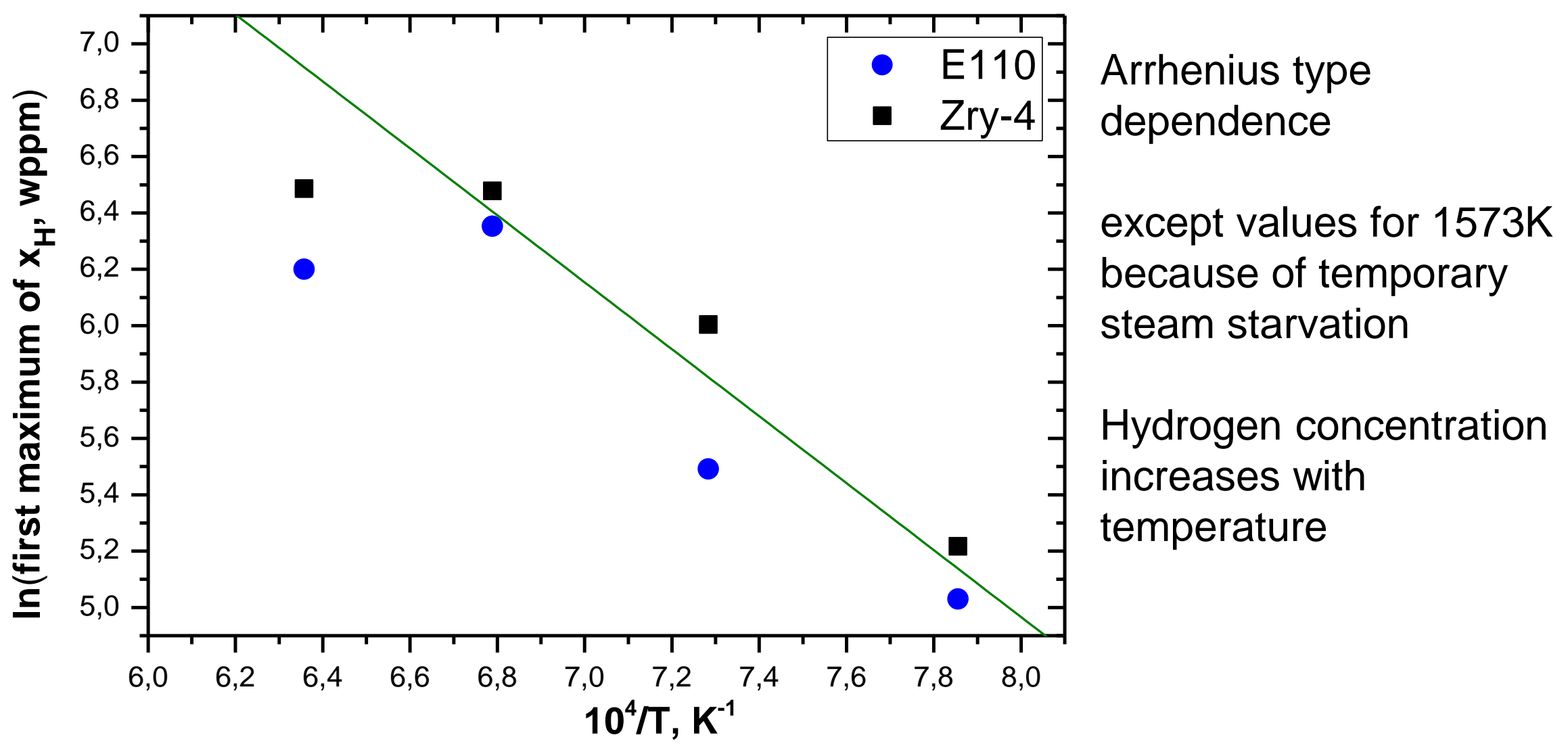




\section{Discussion}

Hydrogen release according the model of Veshchunov and Berdyshev with $\mathrm{t}^{-1 / 8}$
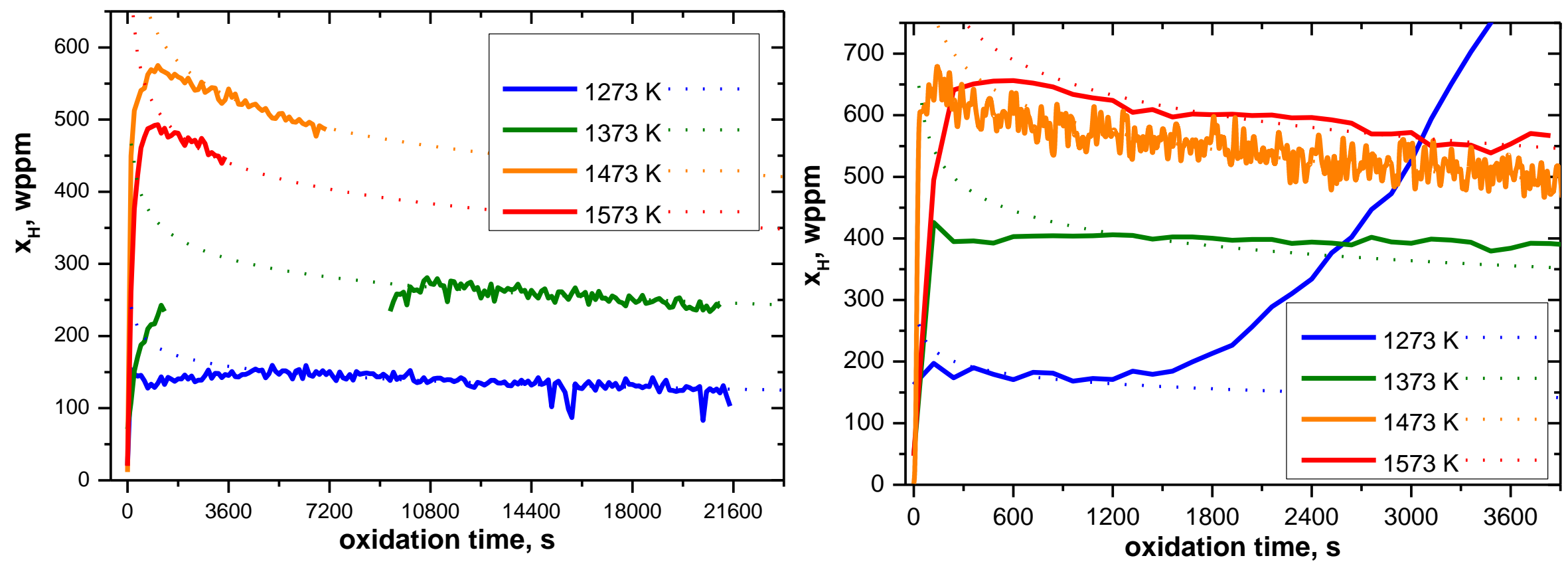


\section{Discussion}

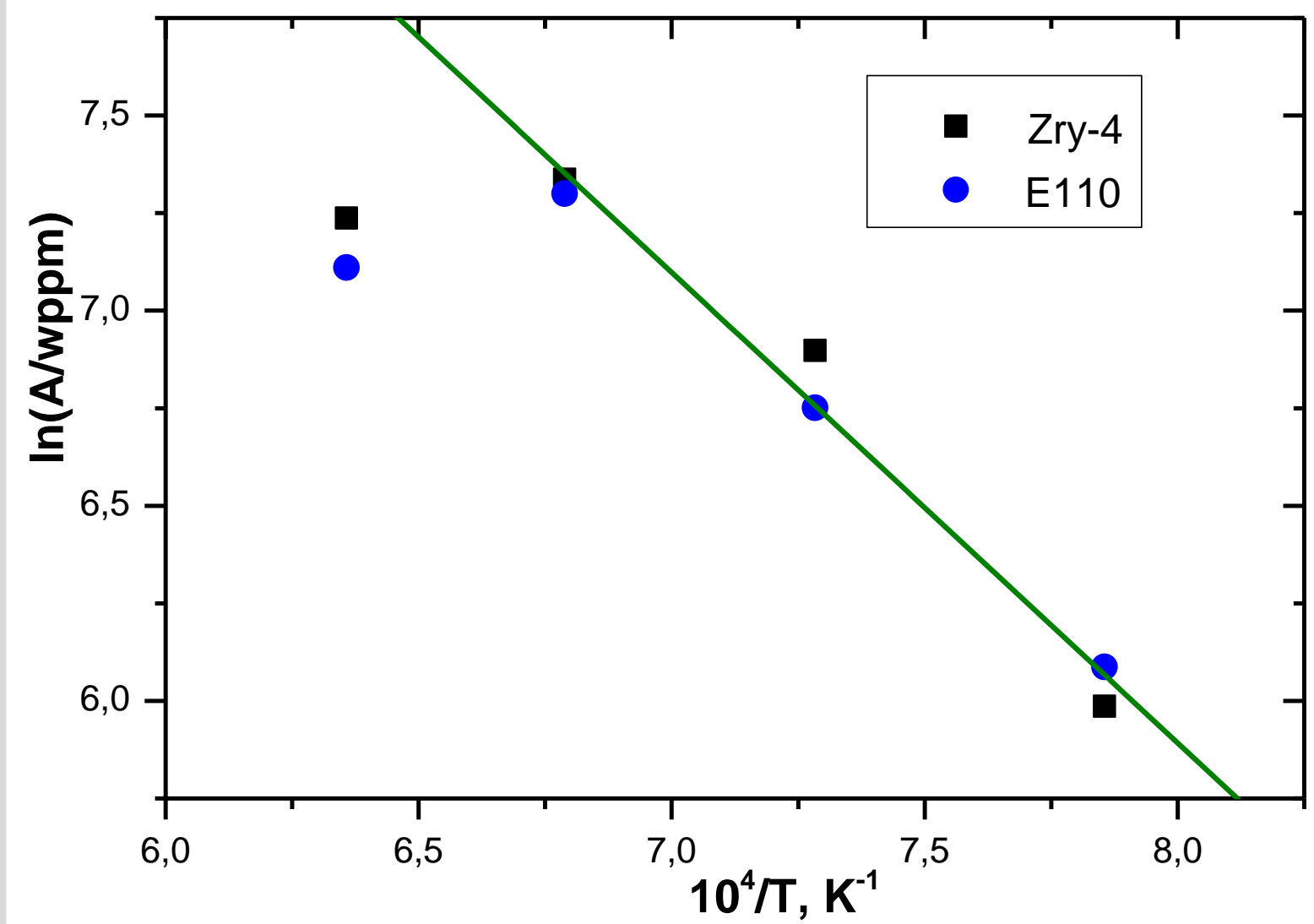

Arrhenius type dependence

except values for $1573 \mathrm{~K}$ because of temporary steam starvation 


\section{Discussion}

Sieverts' law:

$$
\begin{aligned}
x_{H}^{\text {metal }} & =K_{S} \sqrt{p_{H_{2}}} \\
K_{S} & \sim \exp \left(\frac{-H_{s}}{R T}\right) \\
p_{H_{2}} & =\frac{\dot{n}_{H}}{2\left(\frac{\dot{n}_{H}}{2}+\dot{n}_{H_{2} O}+\dot{n}_{A r}\right)} \\
\dot{n}_{H} & =2 \frac{d\left(K_{O}^{m} \sqrt{t}\right)}{d t}=-\frac{K_{O}^{m}}{\sqrt{t}} \\
K_{O}^{m} & \sim \exp \left(\frac{-H_{o}}{R T}\right)
\end{aligned}
$$$$
x_{H}^{\text {metal }} \sim \exp \left(\frac{-\left(H_{s}-H_{O} / 2\right)}{R T}\right)
$$$$
\rightarrow H_{O}>H_{S}
$$$$
\rightarrow \text { The hydrogen source term }
$$
dominates the process not the Sieverts dependence 


\section{Conclusions}

- Very fast hydrogen uptake as long as metallic surface exists or the oxide layer thickness is low enough. It explains the findings in the QUENCHLOCA tests.

- The oxidation rate determines the amount of hydrogen absorbed, not the Sieverts' law.

- After reaching maximal hydrogen concentrations, hydrogen will be released. The hydrogen concentration decreases according to the model of Veshchunov and Berdyshev with $\mathrm{t}^{-1 / 8}$.

- Breakaway can enhance the hydrogen uptake significantly but only if the oxide is not spalled. 


\section{Thanks}

We thank all involved in this investigations in particular our students Marius van den Berg and Camille Goulet.

Thanks to TU Munich (Germany) and PSI Villigen (Switzerland) for providing neutron beam time for these experiments.
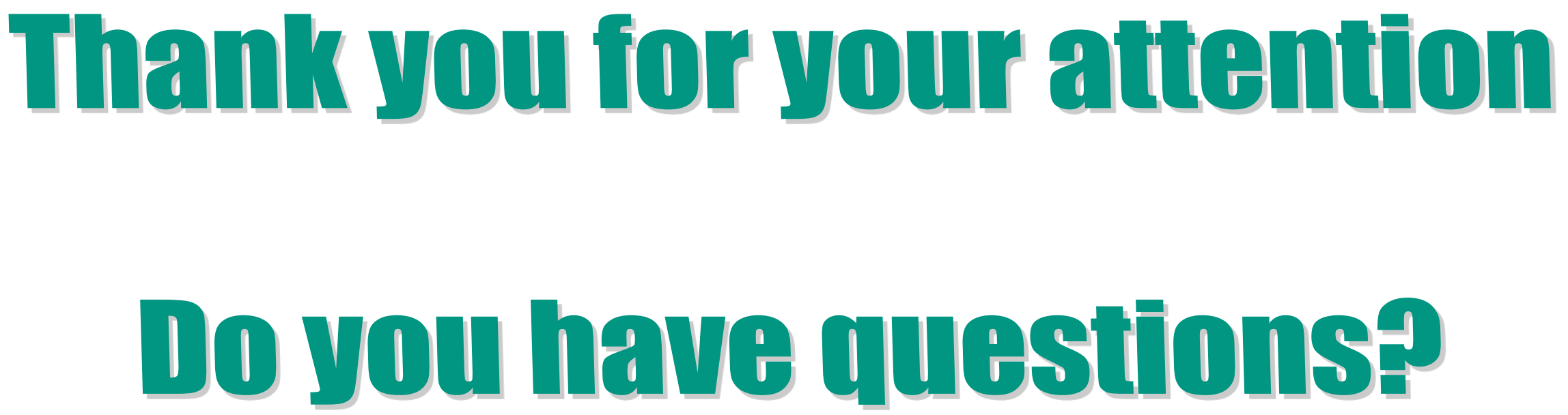


\section{In-situ Investigations of the Hydrogen Uptake of Zirconium Alloys during Steam Oxidation}

\section{Grosse, M. Steinbrueck, B. Schillinger, A. Kaestner}

